\title{
Theoretical Investigation to Corrosion Inhibition Efficiency of Some Chloroquine Derivatives Using Density Functional Theory
}

\author{
Babatunde Temitope Ogunyemia,*, Dayo Felix Latona ${ }^{b}$, Abraham Abiodun Ayindec, Isaiah Ajibade \\ Adejoroc
}

a Department of Chemistry Federal University Otuoke, Bayelsa State, Nigeria

b Department of Chemistry, Osun state University, Oshogbo, Nigeria

c Departement of Chemistry, University of Ibadan, Ibadan, Nigeria

\section{ART I CLE IN F O}

Received: 08 October 2019

Revised: 20 December 2019

Accepted: 29 December 2019

Available online: 31 December 2019

\section{K E Y W O R D S}

Corrosion

Chloroquine

Density functional theory

Inhibition efficiency

\section{A B S T R A C T}

In this work, the potential of corrosion inhibition of four chloroquine derivatives; $N^{4}$-(7-Chloroquinolin-8-ol-4-yl)- $N^{1}, N^{1}$-diethylpentane-1,4 diamine $\left(\mathrm{M}_{2}\right), N^{4-}(7-$ Chloroquinolin-8-amino-4-yl)- $N^{1}, N^{1}$-diethylpentane-1,4 diamine $\left(\mathrm{M}_{3}\right)$ and $N^{4}$-(5-bromo-7-Chloroquinolin-8-amino-4-yl)- $N^{1}, N^{1}$-diethylpentane-1,4-diamine $\left(\mathrm{M}_{4}\right)$ were investigated. Their chemical descriptors which include molecular volume, softness, chemical hardness, electronegativity, fraction $(\Delta N)$ and electrophilicity index $(\omega)$ dipole moments, surface of the molecule, and electronic parameters which include the Еномо (the highest occupied molecular orbital of energy); ELumo (lowest unoccupied molecular orbitals of energy) and energy gap (Е Еuмо-Еномо) were calculated using the DFT/B3LYP/6-311 G approach. The results revealed an established correlation between the electronic structures and the quantum parameters of the studied molecules together with their inhibition efficiency toward corrosion process. Also chloroquine derivatives with $-\mathrm{NH}_{3}$ substituent: $\mathrm{M}_{3}$ and $\mathrm{M}_{4}$ were predicted to have enhanced inhibition efficiency.

\section{GRA P H I C A L A B S TRACT}

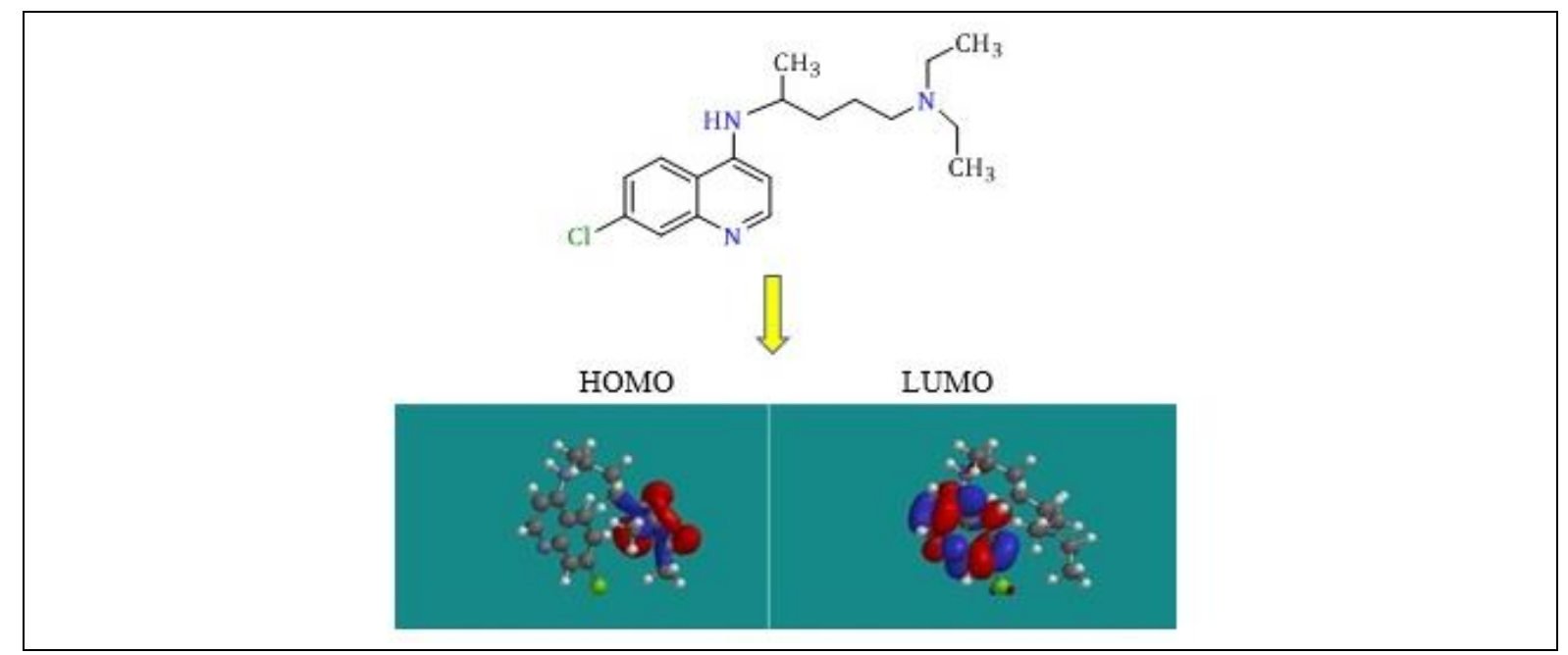

*Corresponding author's E-mail address: btogunyemi@yahoo.com 


\section{Introduction}

Protection of metal surfaces from corrosion is a very active and important industrial and scientific field of research. Metals are exposed to acids, bases and brine solution in different ways and for many reasons. For example, acid solutions are commonly utilized in oil-well acidizing, industrial cleaning, and acid pickling [1-3]. One important means to prevent this corrosion against deterioration of metal is through the use of inhibitor [4-5]. The effectiveness of inhibitors has been associated with the electronic structure as well as their spatial orientation. Most effective and efficient inhibitors have $\pi$-bonds and heteroatoms (P, $\mathrm{S}, \mathrm{N}$ and $\mathrm{O}$ ) with lone pair electrons can inhibit the corrosion of metal in aqueous acid solutions [6,7]. The toxic nature of inorganic and organic inhibitors in the environment $[7,8]$ is leading to search for other environmental friendly inhibitors such as green inhibitors. Green corrosion inhibitors which include plant extracts and drugs [1014] are more environmental friendly. They are biodegradable and characterised as nonharmful molecular structure that is free of heavy metals. Several literatures have reported the use of extracts from plants as effective biocides to tackle bio-corrosion [1517]. The use of drugs including, sulphur drugs, antimalarial drugs, antibacterial, antiviral, antifungal, antineoplastic and analgesic drugs as inhibitors of metal corrosion in various environments has been reported [13-18]. Despite all these, research into better organic inhibitor is still on going.

Apart from its medicinal application as antimalarial drug, the role of chloroquine as corrosion inhibitor of metal has been experimentally reported at different environment [19-20]. Adejoro et al. [20] studied the efficiency of chloroquine $\left(N^{4}-(7-\right.$ Chloroquinolin-4-yl)- $N^{1}, N^{1}$-diethylpentane1,4-diamine) as inhibitor against corrosion of aluminium in ${ }^{1} \mathrm{M} \mathrm{HCl}$ solution experimentally and theoretically. The experimental work provides valuable information on the corrosion inhibition efficiency of the chloroquine $\quad N^{4}$-(7-Chloroquinolin-4-yl)$N^{1}, N^{1}$-diethylpentane-1,4-diamine. However, a total understanding of the inhibitory properties of other derivatives remains uncertain. Experimental tools are helpful in explaining the mechanism of inhibition, but it is often time consuming and expensive. This factor can be investigated using quantum chemical methods so as to give understanding into the quantum chemical descriptors and the interaction between synthesized/hypothetical inhibitors and metal surface [9]. The effectiveness of corrosion inhibitors is closely linked to quantum chemical descriptors: molecular volume, softness chemical hardness, electronegativity, fraction $(\Delta \mathrm{N})$ and electrophilicity index $(\omega)$ dipole moments, surface of the molecule, and electronic parameters: Еном (the highest occupied molecular orbital of energy); $\mathrm{E}_{\text {LUмо }}$ (lowest unoccupied molecular orbitals of energy) and energy gap ( $\left.\mathrm{E}_{\mathrm{Lumo}}-\mathrm{E}_{\text {номо }}\right)$ calculated from the DFT approach. Thus, the continuous advances in hardware and software has made theoretical methods powerful tool for assessing the corrosion inhibition efficiency and quite a numbers of quantum chemical modelling methods have been established to relate the inhibitory effectiveness of organic inhibitors with their molecular properties [21-23]. Therefore, the aim of this research study is to extend the study of the inhibitory properties of chloroquine drug to their derivatives (as shown in Figure 1) using quantum mechanical approach. This approach will probe molecular reactivity descriptors that characterize their inhibitory properties and further elucidate their electronic structures and reactivity toward prediction of their corrosion inhibition efficiency. 
<smiles>CCN(CC)CCCC(C)Nc1ccnc2cc(Cl)ccc12</smiles>

$N^{4}$-(7-Chloroquinolin-4-yl)- $N^{1}, N^{1}$ diethylpentane-1,4 diamine $\left(\mathrm{M}_{1}\right)$<smiles>CCN(CC)CCCC(C)Nc1ccnc2c(N)c(Cl)ccc12</smiles>

$N^{4}$-(7-Chloroquinolin-8-amino-4-yl)- $N^{1}, N^{1-}$ diethylpentane-1,4 diamine $\left(\mathrm{M}_{3}\right)$

Figure 1. Structure of chloroquine derivatives

\section{Experimental}

\section{Computational methodology}

Quantum chemical calculations were carried out using the Spartan' $14 \mathrm{~V}$ 1.1.4. The full optimization started from determining the most stable conformer using the molecular mechanics force fields (MMFF). The results from the MMFF were further re-optimized without any constraint using the density functional theory (DFT) with B3LYP functional methods and 6-311G(d) basis set. In accordance with the approach of Hohenberg and Kohn, 1964; Kohn and Sham, 1965 [24-25], DFT with 6-311G(d) basis set has turned out to be an important tool in modern quantum chemistry because of its flexibility that guarantee reliable theoretical results and its ability to add correlation effect at a reduced computational cost.

The adsorption sites of the inhibiting molecules were predicted using frontier molecular orbitals; (HOMO and LUMO) while the energies of the highest occupied and lowest unoccupied molecular orbitals (E $\mathrm{E}_{\text {номо }}$ and $\mathrm{E}_{\text {Lumo) }}$ of the inhibiting molecules are related to the electron affinity (EA) and ionization<smiles>CCN(CC)CCCC(C)Nc1ccnc2c(O)c(Cl)ccc12</smiles>

$N^{4}$-(7-Chloroquinolin-8-ol-4-yl)- $N^{1}, N^{1}$ diethylpentane-1,4 diamine $\left(\mathrm{M}_{2}\right)$<smiles>CCN(CC)CCCC(C)Nc1ccnc2c(N)c(Cl)cc(Br)c12</smiles>

$N^{4}$-(5-bromo-7-Chloroquinolin-8-amino-4-yl)$N^{1}, N^{1}$-diethylpentane-1,4-diamine $\left(\mathrm{M}_{4}\right)$

potential (IP) respectively using Koopman's theorem [26] as shown in equations 1 and 2 .

$\mathrm{IP}=-\mathrm{E}_{\text {номо }}$

$\mathrm{EA}=-\mathrm{E}_{\mathrm{LUMO}}$

The hardness $(\eta)$ and the electronegativity $(\chi)$ of the inhibiting molecules were calculated according to Parr and Pearson, 1983 [27].

$$
\begin{aligned}
& \eta=-\mu=\left(\frac{\delta \varepsilon^{2}}{\delta \mathrm{N}^{2}}\right)_{\nu(r)}=\frac{I-A}{2} \\
& \chi=-\mu=\left(\frac{\delta \varepsilon}{\delta \mathrm{N}}\right)_{v(r)}=\frac{I+A}{2}
\end{aligned}
$$

Furthermore, the softness of the inhibiting molecules which is expressed as the inverse of the hardness value was calculated according to Chirico and Gramatica, 2012 [28].

$\sigma=\frac{1}{\eta}$

These reactivity descriptors have proven to be helpful in the theory of chemical reactivity. When two systems, the Fe and the inhibitor, are in contact with each other, electrons from the system with lower electronegativity (inhibitor) 
flows to the system with higher electronegativity (Fe) until the chemical potential is equal. The number of electron transferred $(\Delta N)$ is therefore estimated using equation $6[26]$.

$\Delta \mathrm{N}=\frac{\chi \mathrm{Fe}-\chi \mathrm{inh}}{2(\eta \mathrm{Fe}-\eta \text { inh })}$

$\chi_{\text {inh }}$ and $\chi_{\mathrm{Fe}}$ represent electronegativities of the inhibiting molecule and the metal respectively while $\eta_{\text {inh }}$ and $\eta_{\mathrm{Fe}}$ represent the hardness of the inhibiting molecule and metal respectively. The theoretical value of $\chi_{\mathrm{Fe}}(7$ $\mathrm{eV} /$ mole $)$ and $\eta_{\mathrm{Fe}}(0 \mathrm{eV} /$ mole $)$ according to Parr et al., (1999) [29] were used to calculate the number of transferred electrons. The value of back donation of charges was calculated using the following expression:

$\Delta \mathrm{E}_{\text {Back }- \text { donation }}=\frac{\mu}{4}$

The electrophilicity index of the entire molecule which is given in the equation 8, measures the stabilization energy and the tendency of chemical species to obtain addition charge from $\Delta N$ the environment [29].

$\omega=\frac{\mu^{2}}{2 \eta}$

\section{Results and discussion}

DFT is one of the most powerful tools in quantum chemistry. It is the shooting star in theoretical modelling. The structures of the studied chloroquine derivatives are presented in Figure 1. It is apparent in Figure 1 that the studied chloroquine derivatives contain amino group. The frontier molecular orbital structures of the optimised chloroquine derivatives using DFT/B3LYP/6-311G(d) are displayed in (Figure 2a-d). Suggested quantum chemical parameters that may be responsible for the inhibition efficiency of the investigated molecules as obtained from the calculations are: $\mathrm{E}_{\text {номо, }} \mathrm{E}_{\text {Luмо, }}$ Separation energy $\Delta \mathrm{E}$, dipole moment $(\mu)$, $\log \mathrm{P}$, solvation energy ( $\left.\mathrm{E}_{\text {solv }}\right)$, Ovality, Electron Affinity (EA), Ionization Potential (IP), global electrophilicity $(\omega)$, softness $(\sigma)$, chemical hardness $(\eta)$, electronegativity $(\chi)$, total energy of electron transfer $\Delta \mathrm{N}$ and polarizability.

The $\mathrm{E}_{\text {номо }}$ is associated with the electron donating ability of an inhibitor. The increase in the value of $\mathrm{E}_{\text {номо }}$ indicate that the inhibitor as higher tendency to donate electrons to the corresponding lower energy molecular orbital. Therefore, the effectiveness of an inhibitor can be improved by enhancing the transferring process. In Table 1, it is clear that the $\mathrm{E}_{\text {номо values for investigated inhibitors }}$ decrease in the order; $M_{3}>M_{4}>M_{1}>M_{2}$. The highest value of $\mathrm{E}_{\text {номо }}(-5.51 \mathrm{eV})$ for $\mathrm{M}_{3}$, indicates the best inhibitor which gives electrons to the corresponding empty $d$-orbital of the metal ion. However, inhibiting molecules does not only donate electrons to the empty $d$-orbital of the metal ion but electrons are also accepted from the $d$-orbital of the metal. This process leads to formation of the feedback bond. Thus $\mathrm{E}_{\text {Lumo }}$ indicates the ability of an inhibitor to accept electrons from the metal ion which would definitely improve the adsorption and inhibition efficiency of the inhibiting molecule on the metal surface [30]. The $E_{\text {Lumo }}$ for $M_{1}-M_{4}$ follow the order: $\mathrm{M}_{3}>\mathrm{M}_{1}>\mathrm{M}_{2}>\mathrm{M}_{4}$, indicating that the $\mathrm{M}_{3}$ has a better tendency to accept electrons from the corresponding the metal ion. The energy difference $(\Delta \mathrm{E})$ between the HOMO and LUMO of a molecule connects the reactivity of an inhibitor with adsorption on the surface of the metal. A decrease in the $\Delta \mathrm{E}$ value of inhibitors increases the reactivity between the inhibiting molecule and the metal ion and thus increases the binding ability on the metal surface.

This increase in binding ability could lead to an increase in inhibition efficiency (\%IE) of the inhibitor since the energy required to remove the electron from the last occupied orbital will be low. 
Table 1. Quantum chemical reactivity descriptors of some chloroquine derivatives $\mathrm{M}_{1}-\mathrm{M}_{4}$ estimated with DFT/B3LYP/6-311G(d)

\begin{tabular}{ccccc} 
Parameter & $\mathrm{M}_{1}$ & $\mathrm{M}_{2}$ & $\mathrm{M}_{3}$ & $\mathrm{M}_{4}$ \\
$\mathrm{E}_{\text {номо }}(\mathrm{eV})$ & -5.80 & -5.81 & -5.51 & -5.54 \\
$\mathrm{E}_{\text {Luмo }}(\mathrm{eV})$ & -1.91 & -1.96 & -1.72 & -1.97 \\
$\Delta \mathrm{E}(\mathrm{eV})$ & 3.89 & 3.86 & 3.79 & 3.58 \\
$\sigma(\mathrm{eV})$ & 0.513 & 0.518 & 0.526 & 0.559 \\
$\eta(\mathrm{eV})$ & 1.95 & 1.93 & 1.90 & 1.79 \\
$\Delta \mathrm{N}$ & 0.81 & 0.81 & 0.89 & 0.91 \\
Log & 3.73 & 3.34 & 2.92 & 3.75 \\
Ovality & 1.54 & 1.55 & 1.56 & 1.58 \\
PSA $\left(\mathrm{A}^{2}\right)$ & 20.84 & 38.16 & 43.47 & 41.81 \\
$\alpha$ & 68.60 & 69.17 & 69.49 & 71.03 \\
$\mathrm{E}_{\text {solv }}(\mathrm{eV})$ & -22.47 & -26.89 & -26.09 & -20.26 \\
$\mathrm{IP}(\mathrm{eV})$ & 5.80 & 5.81 & 5.51 & 5.54 \\
EA (eV) & 1.80 & 1.96 & 1.72 & 1.97 \\
$\chi(\mathrm{eV})$ & 3.86 & 3.89 & 3.62 & 3.76 \\
$\omega$ & -3.82 & -3.92 & -3.45 & -3.95 \\
$\mathrm{~V}\left(\mathrm{~A}^{3}\right)$ & 346.90 & 352.86 & 357.59 & 376.05 \\
Area $\left(\mathrm{A}^{2}\right)$ & 368.20 & 375.51 & 380.04 & 399.31 \\
DM (debye) & 4.59 & 5.72 & 3.43 & 2.93 \\
$\Delta \mathrm{E}_{\text {back-donation }}$ & -0.97 & -0.97 & -0.91 & -0.94 \\
M.W. (amu) & 319.880 & 335.879 & 334.895 & 413.791 \\
\hline
\end{tabular}

Note: $\eta=$ chemical hardness, $\alpha=$ polarizability, PSA=polar surface area, $\omega=$ global electrophilicity index, $\Delta \mathrm{E}=$ =nergy difference, $\chi=$ =lectronegativity, $\sigma=$ softness, $\Delta \mathrm{N}=$ Electron transfer, Esolv= solvation energy, $\mathrm{V}=$ Volume, $\mathrm{M} . \mathrm{W}=$ Molecular Weight and $\mathrm{DM}=$ dipole moment

Figure 2. Frontier molecular orbital structures of $\mathrm{M}_{1}-\mathrm{M}_{4}$ using DFT/B3LYP/6-311G(d)
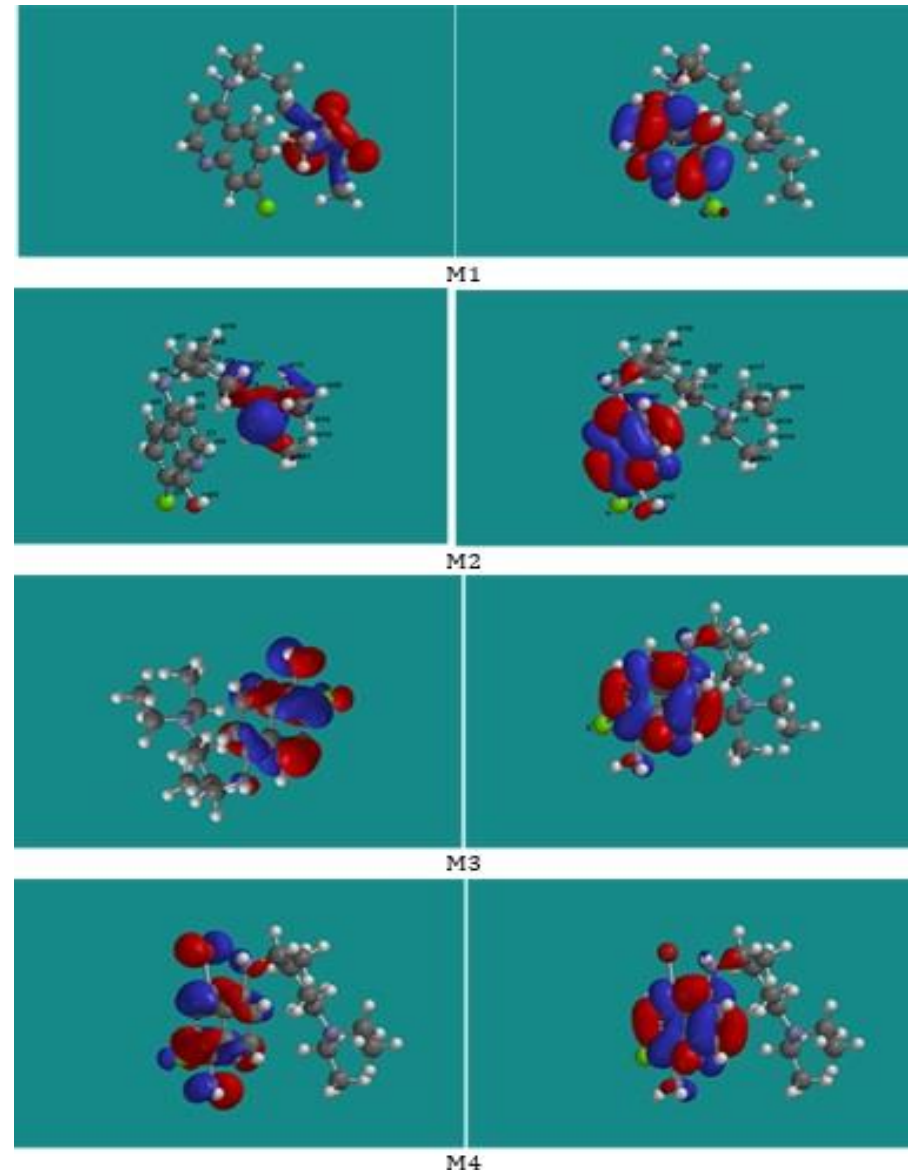
The value of $\Delta \mathrm{E}$ for the four molecules (Table 1) decreased in the following order: $M_{4}>M_{3}>M_{2}>M_{1}$. Based on this order, it is assumed that $M_{4}$ has the least energy difference, higher reactivity and therefore inhibit better than other molecules. The ability of an inhibitor to bind to the surface of the metal enhanced as the energy of HOMO increased and energy of LUMO reduced. In an attempt to further evaluate the molecular reactivity and stability of the inhibitors, the absolute hardness and softness which are the quantum reactivity descriptors were determined. The absolute softness and hardness are related to soft and hard solutions through the theory of acid and base. Chemical hardness indicated the resistance to deformation or polarization of the electron cloud of molecules, atoms or ion with minor perturbations of the chemical reaction. The absolute hardness for the four molecules was reduced in the following order: $\mathrm{M}_{4}<\mathrm{M}_{3}<\mathrm{M}_{2}<\mathrm{M}_{1} . \mathrm{M}_{4}$ with the lowest hardness value $(1.79 \mathrm{eV})$ compared with other compounds had the lowest $\Delta \mathrm{E}$ while $\mathrm{M}_{1}$ with the highest hardness value had the highest $\Delta \mathrm{E}$. The softness followed a reverse trend of hardness values: $\mathrm{M}_{1}<\mathrm{M}_{2}<\mathrm{M}_{3}<\mathrm{M}_{4}$. This result was consistent with the general belief that hard molecules should have large $\Delta \mathrm{E}$ and a soft molecule should have small $\Delta \mathrm{E}$ [5]. Therefore, $\mathrm{M}_{3}$ and $\mathrm{M}_{4}$ are expected to have higher inhibition efficiency than that of the $M_{1}$ and $M_{2}$ since the lowest global hardness value (i.e. the highest global softness) was likely the highest inhibition efficiency.

Electronegativity is associated with the tendency of an atom in a molecule to attract the shared pair of electron to itself. The order of electronegativity values of studies molecules (Table 1) is as follow: $\mathrm{M}_{3}<\mathrm{M}_{4}<\mathrm{M}_{1}<\mathrm{M}_{2}$. Also, the electronegativity difference between the inhibitor and the metal follows the order of $M_{2}>M_{1}>M_{4}>M_{3}$.
Following the Sanderson's principle of electronegativity equalization, $M_{2}$ with a low electronegativity difference and electronegativity gets to equalization quickly and therefore low reactivity is expected, which, in turn, indicates low inhibition efficiency [31]. The Dipole Moment $(\mu)$ of inhibiting molecules predicts the direction of the corrosion inhibition process. It gives information about the polarity in the bond of a molecule and distribution of electrons in the molecules [9]. The high value in dipole moment of inhibitors tends to increase their adsorption on the surface of a metal to provide better inhibition. The $\mu$ of the studied molecules is observed in the following order: $\mathrm{M}_{2}>\mathrm{M}_{1}>\mathrm{M}_{3}>\mathrm{M}_{4}$. Although, there is inconsistency with the use of $\mu$ to predict the direction of a corrosion inhibition reaction in literatures; however, it is well known that adsorption of polar compounds with high $\mu$ on the surface of the metal should enhance inhibition efficiency. The trend in polarizability of the studied molecules follows the order: $M_{4}>M_{3}>M_{2}>M_{1}$ indicating that $\mathrm{M}_{4}$ might be having better inhibition efficiency. The inhibition efficiencies of the studied molecules with respect to polarizability could therefore be in the following order: $M_{4}>M_{3}>M_{2}>M_{1}$.

The number of electrons transferred $(\Delta N)$ in a molecule is related to the ability of a molecule to donate electrons to the metals surface. The $\Delta \mathrm{N}$ values for the four studied molecules ranges from 0.81-0.91. Higher value of $\Delta \mathrm{N}$ indicates greater tendency to donate electrons to the electron deficient site and consequently, greater tendency to interact and adsorb on the metal surface. $\Delta \mathrm{N}$ for molecules $\mathrm{M}_{1}-\mathrm{M}_{4}$ increases in the following order: $M_{4}>M_{3}>M_{2} \approx M_{1}$. The largest proportion of electron transferred $(\Delta \mathrm{N})$ is associated with molecule $\mathrm{M}_{4}(0.91)$, while the lowest proportion is associated with $\mathrm{M}_{1}$ 
(0.81) and $\mathrm{M}_{2}(0.81)$ respectively and hence the lowest inhibition efficiency. In a simple model of charge transfer for donation and back donation of charges [32], an electronic back donation process can occur as a result of the interaction between the inhibiting molecule and the surface of a metal. Back donation charges results from Table 1 shows that electronic back donation process can take place during the process of interaction between the studied molecules and metal ions since their values ( -0.91 to -0.97 e) are less than zero. The charges transferred to the molecule, are energetically favoured when $\eta>0$ and $\Delta \mathrm{E}_{\text {Back-donation }}<0$. Therefore, $\mathrm{M}_{3}$ and $\mathrm{M}_{4}$ could be more energetically favoured than $\mathrm{M}_{1}$ and $\mathrm{M}_{2}$. The result is consistence the concept that state that if both charge transfer (i.e. to the molecule and backdonation processes from the molecule) occur, the change in energy is directly proportional to the hardness of the molecule in equation 2.6. Global electrophilicity index $(\omega)$ provides information on the nucleophilicity and electrophilicity nature of inhibiting molecule. Inhibitor with a high electrophilic index act as electrophile while low electrophilicity act as nucleophile. The electrophilicity values (Table 1) of the studied molecules are such that $\mathrm{M}_{4}>\mathrm{M}_{2}>\mathrm{M}_{1}>\mathrm{M}_{3}$.

It was also found that the values of $\log \mathrm{P}$ are closely related to the corrosion inhibition efficiencies of the investigated chloroquine derivatives. Eddy and Ebenso (2010) [33], reported that $\log P$ is responsible for the hydrophobicity (property of a molecule to repel water) of a molecule. Hydrophobicity will increase when the solubility of the molecule in water decreases. In corrosion studies, hydrophobicity can be related to the process at which oxide/hydroxide layer which retards the corrosion process are formed on the surface of the metal. The results obtained for $\log \mathrm{P}$ showed that the inhibition efficiencies of the investigated chloroquine derivatives are likely to increase in the following order $M_{3}>M_{2}>M_{1}>M_{4}$. Molecular volume and weight are quantum parameters that determine molecular size and effective surface coverage. These invariably determine how effective a molecule can be adsorbed on and cover metal surface, thereby isolating it from the corroding environment. The Molecular volume and weight absolute hardness for the four studied molecules increases in the following order: $M_{4}>M_{3}>M_{2}>M_{1}$. As the value of this parameter increases, so also the likely corrosion inhibition potentials of the molecules increase [12].

\section{Conclusion}

The molecular reactivity descriptors of four chloroquine derivatives were probed in order to elucidate their electronic structures, reactivity and predict their efficiency toward corrosion inhibition using quantum mechanical method. The result obtained from DFT at B3LYP/6-311G(d,p) basis set suggests a correlation between electronic structures and quantum parameters of four chloroquine derivatives and their inhibition efficiency toward corrosion process. It was found that the correlations are useful in designing chloroquine inhibitors with suitable substituents capable donating electrons to the surface of the metal. $\mathrm{M}_{3}$ and $\mathrm{M}_{4}$ are expected to have the highest inhibition efficiency due to their high $\mathrm{E}_{\text {номо, }} \Delta \mathrm{N}$ and lowest $\Delta \mathrm{E}$ values which would allow effective electron transfer and thus a better performance as corrosion inhibitor.

\section{Acknowledgment}

The authors acknowledge the Department of Chemistry, University of Ibadan for the use of the computational laboratory.

\section{Disclosure statement}


No potential conflict of interest was reported by the authors.

\section{References}

[1] M.V. Fiori-Bimbi, P.E. Alvarez, H. Vaca, C.A. Gervasi, Corr. Sci., 2015, 92, 192-199.

[2] B.E.A. Rani, J.B.B. Bai, Int. J. Corros., 2012, 2012, 380217.

[3] A.A. Al-Amiery, F.A. Binti Kassim, A.A.H. Kadhum, A.B. Mohamad, Sci. Rep., 2016, 6, 19890.

[4] A.S. Fouda, A.A. Nazeer, M. Ibrahim, M. Fakih. J. Korean Chem. Soc., 2013, 57, 272278.

[5] V.G. Vasudha, K.S. Priya, Chem. Sci. Rev. Lett., 2014, 2, 435-443.

[6] A.S. Fouda, M.A. Ismail, A.S. Abousalem, G.Y. Elewady, RSC Adv., 2017, 7, 4641446430.

[7] A. peter, I.B. Obot, S.K. Sharma, Int. J. Indust. Chem., 2015, 6, 153-164.

[8] M. Chigondo, F. chigondo, J. Chem., 2016, 2016, 6208937.

[9] E.E. Ebenso, D.A. Isabirye, N.O. Eddy, Int. J. Mol. Sci., 2010, 11, 2473-2498.

[10] S. Marzorati, L. Verotta, S.P. Trasatti, Molecules, 2019, 24, 48.

[11] Z.Z. Tasić, M.B. Petrović Mihajlović, A.T. Simonović, M.B. Radovanović, M.M. Antonijević, Sci. Rep., 2019, 9, 14710.

[12] M.A. Quraishi, A. Singh, V.K. Singh, D.K. Yadav, A.K. Singh, Mater. Chem. Phys., 2010, 122, 114-122.

[13] I.B. Obot, N.O. Obi-Egbedi, Der Pharm. Chem., 2009, 1, 106-123.

[14] I.B. OboT, N.O. Obi-Egbedi, J. Appl. Electrochem., 2010, 40, 1977-1983.

[15] J. Narenkumar, P. Parthipan, A.U. Raja Nanthini, G.B. Kadarkarai Murugan, A. Rajasekar, 2017, 3 Biotech , 7, 133.

[16] J. Bhawsar, P.K. Jain, J. Preeti, Alexand. Eng. J., 2015, 54, 769-775.
[17] S.M. Bhola, G. Singh, B. Mishra, Int. J. Electrochem. Sci., 2013, 8, 5635-5642.

[18] R.K. Pathak, M. Pratiksha, Int. J. Sci. Res., 2016, 5, 671-675.

[19] S.U. Ofoegbu, P.U. Ofoegbu, ARPN J. Eng. Appl. Sci., 2012, 272-276.

Ofoegbu, S. U., \& Ofoegbu, P. U. (2012). Corrosion inhibition of mild steel in $0.1 \mathrm{M}$ hydrochloric acid media by chloroquine diphosphate. ARPN Journal of Engineering and Applied Sciences, 7(3), 272-276.

[20] I.A. Adejoro, D.C. Akintayo, C.U. Ibeji, Jordan J. Chem., 2016, 11, 38-49.

[21] K.F. Khaled, Corr. Sci., 2011, 53, 34573465.

[22] A. Zarrouk, B. Hammouti, T. lakhlifi, M. Traisnel, H. Vezin, F. Bentiss, Corr. Sci., 2015, 90, 572-584.

[23] I.B. Obot, D.D. Macdonald, Z.M. Gasem, Corr. Sci., 2015, 99, 1-30.

[24] P. Hohenberg, W. Kohn, Phys. Rev., 1964, 140, B864-B871.

[25] W. Kohn, L.J. Sham, Phys. Rev., 1965, 140, A1133-A1138.

[26] R.G. Pearson, Proc. Natl. Acad. Sci. U. S. A., 1986, 83, 8440-8441.

[27] R.G. Parr, R.G Pearson, J. Am. Chem. Soc., 1983, 105, 7512-7516.

[28] N. Chirico, P. Gramatica, J. Chem. Inf. Model., 2012, 52, 2044-2058.

[29] P.G. Parr, L.V. Szentpaly, S. Liu, J. Am. Chem. Soc., 1999, 121, 1922-1924.

[30] N.A. Wazzan, F.M. Mahgoub, Open J. Phys. Chem., 2014, 4, 6-14.

[31] P. Udhayakala, T.V. Rajendiran, J. Chem. Boil. Phys. Sci., 2012, 2, 172-183.

[32] K. Adardour, R. Touir, M. El-Bakri, Y. Ramli, M. Touhami, H. El-Kafsaoui, C. Mubengayi, E.M. Essassi, Res. Chem. Intermed., 2013, 39, 4175-4188.

[33] N.O. Eddy, E.E. Ebenso, J. Mol. Model., 2010, 16, 1291-1306.

How to cite this manuscript: Babatunde Temitope Ogunyemi, Dayo F. Latona, Ajibade Isaiah Adejoro, Abraham A. Ayinde, Theoretical Investigation to Corrosion Inhibition Efficiency of Some Chloroquine Derivatives Using Density Functional Theory, Adv. J. Chem. A, 2020, 3(4), 485-492.

Copyright (C) 2020 by SPC (Sami Publishing Company)+ is an open access article distributed under the Creative Commons Attribution License, which permits unrestricted use, distribution, and reproduction in any medium, provided the original work is properly cited. 